\section{Clonal integration of the invasive plant Wedelia trilobata (L.) Hitch in stress of flooding type combination}

Endang Saptiningsih 1,2 Kumala Dewi ${ }^{3}$ S. Santosa, ${ }^{3}$ Yekti A. Purwestri ${ }^{4}$

${ }^{1}$ Faculty of Biology, Gadjah Mada University, Yogyakarta; ${ }^{2}$ Laboratory of Plant Physiology, Faculty of Sciences and Mathematics, Diponegoro University, Semarang; ${ }^{3}$ Laboratory of Plant Physiology, Faculty of Biology, Gadjah Mada University, Yogyakarta; ${ }^{4}$ Laboratory of Biotechnology, Faculty of Biology, Gadjah Mada University, Yogyakarta, Indonesia

\begin{abstract}
The clonal invasion of Wedelia trilobata (L.) Hitch has spread to riverside and edges of mangrove areas, which leads to the formation of flooding-stressed areas such as waterlogged and submergence. This study purpose to investigate the clonal integration mechanism of $W$. trilobata in stress of flooding type combination. This study was conducted in greenhouse with four combinations of flooding treatment on mother ramet (MR) and daughter ramet (DR) for 25 days. Several parameters were measured are shoot growth, relative growth rate (RGR), biomass, biomass allocation, adventitious root growth, and lenticel hypertrophy. The highest clonal performance was observed for the combination of field capacity (MR)waterlogged (DR). The lowest performance was observed for the combination of waterlogged (MR)-submergence (DR). There were decreases in the shoot growth, RGR, and biomass allocation in mother ramet. However, adventitious root growth and lenticel hypertrophy increased in daughter ramet. The increase of flooding pressure suppresses the performance of clonal plants. Clonal integration buffered clonal plants by improving the performance of daughter ramet in the combination of flooding type. The clonal integration has facilitated $W$. trilobata invasion in inundated areas.
\end{abstract}

\section{Introduction}

Invasive plants are often aggressive weeds that spread rapidly and disrupt the community structure of native plants by replacing them. The invasion of these plants affects ecosystem composition and diversi- ty, such as lead to the alteration of micronutrient, hydrology, increase the frequency of land fires. ${ }^{1}$ Furthermore, the ecosystem disruption caused by foreign species invasion can result in economic sector collapses, environmental damage, and health problems. ${ }^{2}$

The majority of invasive plants are clonal plants consisting of ramets connected by stolons or rhizomes. ${ }^{3}$ Ramets include mother and daughter ramets or old and young ramets. The main character of clonal plants is clonal integration, partitioning resources between ramets. ${ }^{4}$ Stressed environmental conditions could affect to resource translocation from unstressed ramet to be stressed ramet. Therefore, increasing number of resources will enhance the recipient ramets survival. ${ }^{5}$ The influence of clonal integration on ramets performance can be measured from growth, biomass allocation and morphological characters. ${ }^{6}$ The performance improvement facilitates the invasive plants in the environmentally stressed area. ${ }^{7}$

Flooding stress on plants is categorized based on the location of water accumulation. When the flooding occurs in the rooting system it is termed waterlogged conditions. However, if the flooding is found all over the plants' body, i.e, the plants are sunk in the water, it is called submergence. ${ }^{8}$ This condition brings a negative effect on the plant, i.e, inhibits gas diffusion such as $\mathrm{O}_{2}$ and $\mathrm{CO}_{2}$, alters soil electrochemical components, energy crisis, ROS (Reactive Oxygen Species) production, and water deficiency. ${ }^{9}$

Wedelia trilobata (L.) is a clonal plant included in 100 worst invasive species worldwide. ${ }^{10}$ It is reported that $W$. trilobata threatens vegetation biodiversity in several areas including ecotone between terrestrial and mangrove ecosystems. ${ }^{11,12} \mathrm{~W}$. trilobata has invaded riparian (riverside) and mangrove areas. $^{13}$ In addition, both waterlogged and submergence flooding types have been commonly found in riparian zones. ${ }^{14}$

The clonal plants spread horizontally through heterogeneous environmental conditions such as nutrient availability. ${ }^{3}$ Therefore, clonal plants can experience in stress of flooding type combination on their constituent ramets. Ramets can be found in waterlogged conditions and others under submergence condition, even if the same clonal plant. ${ }^{12}$ Stated that the clonal integration strategy plays a pivotal role in $W$. trilobata invasion. Accordingly, this study has been conducted to investigate the clonal integration of $\mathrm{W}$. trilobata under flooding type combinations. ${ }^{12}$
Correspondence: Endang Saptiningsih, Faculty of Biology, Gadjah Mada University, 55281 Yogyakarta, Indonesia; Laboratory of Plant Physiology, Faculty of Sciences and Mathematics, Diponegoro University, 50275 Semarang, Indonesia.

Tel.: +62.274.580839; +62.274.6492354

E-mail: saptiningsihe@yahoo.co.id

Key words: Wedelia trilobata, clonal integration, invasive, waterlogged, submergence.

Acknowledgments: Authors would like to thank the Directorate General of Higher Education, Ministry of Research Technology and Higher Education, the Republic of Indonesia that give financial support to the Doctoral Program in Gadjah Mada University. Acknowledgements are also given to the Directorate of Research and Community Service, Directorate General for Research and Development, Ministry of Research, Technology and Higher Education for the research financial support (contract number: 007/SP2H/LT/DRPM/V/2017, 5 May 2017).

Contributions: ES, collecting, analyzing the data, writing the manuscript; $\mathrm{KD}$, writing and reviewing the manuscript; $\mathrm{S}$, design; YAP, analyzing the data.

Conflict of interest: the authors declare no potential conflict of interest.

Funding: funding this research from Directorate of Research and Community Service, Directorate General for Research and Development, Ministry of Research, Technology and Higher Education (contract number: 007/SP2H/LT/DRPM/V/2017, 5 May 2017)

Received for publication: 8 December 2018. Accepted for publication: 24 December 2018.

This work is licensed under a Creative Commons Attribution-NonCommercial 4.0 International License (CC BY-NC 4.0).

(C) Copyright E. Saptiningsih et al., 2019 Licensee PAGEPress srl, Italy

International Journal of Plant Biology 2019; 10:7526 doi:10.4081/pb.2018.7526

\section{Materials and Methods}

\section{Sample preparation}

W. trilobata samples were taken from Semarang, Central Java, Indonesia. The clonal plants of $W$. trilobata were propagated vegetatively for two years. The age of the clonal plants was 3 months after plantation. Stolons (2 nodes) were planted in sand and compost mixture (2:1). After 1 month, stolons were transferred into plastic 
pots with river sand medium. Seedlings were fertilized every week with $32: 10: 10$ $\mathrm{N}: \mathrm{P}: \mathrm{K}$ liquid fertilizer and watered every day until seedling stolon length was 50-55 $\mathrm{cm}$. Daughter ramets were produced by planting the node (the second node from apical stolon) into a separate plastic pot containing the river sand medium. Roots grew 10 days after planting.

\section{Flooding stress treatment}

Mother ramets were taken when the stolon length was about $51.79 \pm 1.99 \mathrm{~cm}$ with the number of leaves 14 and leaf area $142.36 \pm 3.99$. For daughter ramets were used stolon length was about $36.68 \pm 2.08$ $\mathrm{cm}$ with a number of leaves around 6-8 and leaf area $67.55 \pm 2.47$. Twenty clonals were divided into four combinations of flooding stress ( 5 clonals for each treatment group). Specifically, there were six clonals in control group, which were measured at the beginning of treatment $(\mathrm{H}-0)$.

\section{Measurement}

Destructive measurements were done to mother and daughter ramets parameters before flooding stress treatment $(\mathrm{H}-0)$ to obtain primary data of leaf area, biomass, and biomass allocation. The parameters were measured are the root biomass $_{\text {(mother/daughter), shoot }}$ biomass $_{(\text {mother/daughter) }}$, clonal biomass, shoot mass ratio (SMR), and root mass ratio (RMR).

Stolon length and the number of leaves were measured through non-destructive measurements. At the end of treatment both mother and daughter ramet parameters were measured, i.e., healthy and damaged leaves number, leaf area, stolon length, stolon increase rate, ramets biomass (root biomass $_{(\text {parental/seedlings) }}$ and shoot biomass $_{(\text {mother/daughter })}$ ), biomass allocation (SMR $_{\text {(mother/daughter), }} \mathrm{RMR}_{\text {(mother/daughter) }}$, and $\operatorname{ArMR}_{\text {(mother/daughter) }}=$ adventitous root biomass/total of clonal biomass), and relative growth rate (RGR), including root RGR, crown RGR, and clonal RGR.

In addition, morphological characters were also observed to obtain information about clonal adaptation under flooding stress such as the number of adventitious roots (ARs) along with its length and wet mass as well as lenticel hypertrophy.

\section{Statistical analysis}

One-way analysis of variance (ANOVA) and LSD test with significance $\mathrm{P}<0.05$ were conducted to analyze clonal integration and flooding stress type influence toward shoot growth, RGR, biomass, biomass allocation, and seeds morphological characters. The analyses were performed using SPSS 16.0 (SPSS, Chicago, Illinois, USA).

\section{Results}

\section{Shoot growth}

The flooding types combination treatments for 25 days affected the shoot growth of clonal plants. There are significant differences in the shoot growth parameters except for stolon length of mother ramets (Table 1). Treatment FC-W group caused highest shoot growth supported by the highest number of healthy leaves and leaf area. However, treatment FC-S caused the highest damaged leaves, around $7.60 \pm 0.24$ per plant, leading to the lowest number of healthy leaves and leaf area (Table 1).

Moreover, daughter ramets growth was significantly influenced by the flooding type combination (Table 1). All daughter ramets growth parameters in each flooding type combination were significantly different $(\mathrm{P}<0.05)$. Treatment $\mathrm{FC}-\mathrm{W}$ group showed the highest increase of stolon length, healthy leaves, and leaf area, as it had the lowest number of damaged leaves among the other treatments. On the other hand, W-S treatment had the lowest daughter ramet growth with the highest damaged leaves number, around $6.00 \pm$ 0.00 .

\section{Relative growth rate}

There were significant differences in RGR parameters among all flooding type combination (Figure 1). Overall, the FC-W group had the highest RGR, while W-S had the lowest. In addition, FC-S group showed the lowest shoot RGR of mother ramets and root RGR of daughter ramets.

\section{Biomass}

The flooding type combination increased the biomass of clonal, mother and daughter ramets, which were significantly different among all treatment $(\mathrm{P}<0.05)$ (Figure 2). The highest biomass was obtained from FC-W group (biomass of clonal, mother and daughter ramet). The W$\mathrm{S}$ group had the lowest seedlings biomass and total clonal number (Figure 2).

\section{Biomass allocation}

The biomass allocation of each treatment was significantly different $(\mathrm{P}<0.05)$ including RMR, SMR, ArMR of both mother and daughter ramets (Figure 3). The pattern biomass allocation was similar among the FC-W, FC-S, and W-W treatments. The highest biomass allocation was observed in daughter ramet shoots followed by mother ramet shoots, mother ramet roots, daughter ramet roots and adventitious roots of daughter ramet. The lowest biomass was allocated to mother ramet adventitious roots. In addition, the W-S treatment group showed the highest biomass allocation in mother ramet shoots, but the lowest allocation was found in mother ramet adventitious roots.

\section{Morphological characters}

Overall, morphological adaptations were observed in all treatment groups, but

Table 1. The influence of flooding type combination on stolon length, an increase of stolon length, healthy leaves number, number of damaged leaves and leaf area.

\begin{tabular}{lccccc} 
Ramet & Parameters & FC-W & FC-S & W-W \\
\multirow{2}{*}{ Mother } & Stolon length $(\mathrm{cm})$ & $51.50 \pm 0.77 \mathrm{a}$ & $52.34 \pm 0.91 \mathrm{a}$ & $52.18 \pm 0.63 \mathrm{a}$ & $53.70 \pm 1.13 \mathrm{a}$ \\
& Increase of stolon length $(\%)$ & $1.25 \pm 0.21 \mathrm{a}$ & $1.24 \pm 0.15 \mathrm{a}$ & $1.05 \pm 0.18 \mathrm{a}$ & $1.37 \pm 0.19 \mathrm{a}$ \\
& Healthy leaves number & $13.40 \pm 0.24 \mathrm{a}$ & $6.80 \pm 0.37 \mathrm{~d}$ & $12.40 \pm 0.24 \mathrm{~b}$ & $9.60 \pm 0.24 \mathrm{c}$ \\
& Damaged leaves number & $0.60 \pm 0.24 \mathrm{~d}$ & $7.60 \pm 0.24 \mathrm{a}$ & $1.60 \pm 0.24 \mathrm{c}$ & $4.40 \pm 0.24 \mathrm{~b}$ \\
& Leaf area $\left(\mathrm{cm}^{2}\right)$ & $137.74 \pm 2.60 \mathrm{a}$ & $47.85 \pm 2.39 \mathrm{~d}$ & $125.18 \pm 2.20 \mathrm{~b}$ & $103.04 \pm 2.61 \mathrm{c}$ \\
Daughter & Stolon length $(\mathrm{cm})$ & $130.78 \pm 1.27 \mathrm{a}$ & $67.76 \pm 1.95 \mathrm{c}$ & $108.40 \pm 1.48 \mathrm{~b}$ & $47.80 \pm 0.93 \mathrm{~d}$ \\
& Increase of stolon length (\%) & $256.29 \pm 6.74 \mathrm{a}$ & $89.55 \pm 3.47 \mathrm{c}$ & $188.19 \pm 5.54 \mathrm{~b}$ & $31.03 \pm 0.8 \mathrm{~d}$ \\
& Healthy leaves number & $15.60 \pm 0.24 \mathrm{a}$ & $10.60 \pm 0.40 \mathrm{c}$ & $14.40 \pm 0.24 \mathrm{~b}$ & $7.20 \pm 0.50 \mathrm{~d}$ \\
& Damaged leaves number & $2.40 \pm 0.24 \mathrm{c}$ & $5.40 \pm 0.40 \mathrm{a}$ & $3.60 \pm 0.24 \mathrm{~b}$ & $6.00 \pm 0.00 \mathrm{a}$ \\
& Leaf area $\left(\mathrm{cm}^{2}\right)$ & $155.45 \pm 1.85 \mathrm{a}$ & $92.18 \pm 1.78 \mathrm{c}$ & $136.60 \pm 2.42 \mathrm{~b}$ & $63.84 \pm 3.98 \mathrm{~d}$ \\
\hline
\end{tabular}

Mean $\pm S E(n=5)$ in different letters show significant differences $(P<0.05)$ between flooding stress types. 
the adaptations were mostly found in mother ramet at the $\mathrm{W}-\mathrm{W}$ treatment group involving adventitious roots and lenticel hypertrophy. Changes were least observed in FC-W treatment group. There was a significant increase in the development of daughter ramet adventitious roots in FC-S and $\mathrm{W}-\mathrm{S}$, but a decrease in the $\mathrm{W}-\mathrm{W}$ and FC-W treatment groups. Furthermore, the highest daughter ramet lenticel hypertrophy occurred in W-W group by around $34.60 \pm$ 1.36. Meanwhile, the lowest lenticel hypertrophy occurred in FC-W group or $2.40 \pm 0.24$ (data not shown).

\section{Discussion}

Wedelia trilobata (L.) is perennial herb originating from South America that is now widely spread into South China, Fiji, Sri Lanka, Micronesia, and Indonesia. ${ }^{13}$ This plant has been known as an invasive weed that is supported by its clonal integration as the main characteristic of the clonal plant. The clonal integration between ramets facilitates resources distribution under environmental stress and influences the clonal performance. ${ }^{15}$

The highest clonal biomass was found in FC-W flooding type combination, followed by W-W, FC-S, and W-S (Figure 2). Likewise, clonal relative growth rate results showed the same pattern as biomass (Figure 1). The waterlogged condition leads to anoxia and hypoxia conditions that further cause an energy crisis in the plant. This condition inhibits root development and also prevents water and nutrients to be absorbed. ${ }^{16}$

Under submergence conditions light radiation is blocked, $\mathrm{CO} 2$ diffusion and photosynthesis decreases in the shoot, further causing anaerobic conditions in the root area. ${ }^{8}$ The strongest flooding pressure was administered to the W-S group, while the weakest given to FC-W group (Table 2). It can be seen in Figure 1 and Figure 2, the increase of flooding stress on ramets reduced the clonal performance. Xiao et al. reported that water depth in flooding stress treatment to daughter ramet of Spartina alterniflora leads to the decrease of shoot biomass and clonal rhizome. ${ }^{17}$ Alkaline stress treatment to Leymus chinensis daughter ramet leads to biomass decrease on ramets and clonal level. ${ }^{18}$

Flooding stress is an environmental stress that restrains live resource availability such as nutrients, gas diffusion, and light for photosynthesis. ${ }^{19}$ The flooding type combination treatment caused differences in resource availability between parental seeds and seedlings, which led to a variety of biomass allocation in each treatment (Figure 3). The most significant differences were observed in the W-S treatment group, where the highest biomass

Table 2. Experimental design.

\begin{tabular}{lcc} 
Combination of flooding type & \multicolumn{2}{c}{ Flooding types } \\
& Mother ramets & Daughter ramets \\
FC-W & Field capacity & Waterlogged \\
FC-S & Field capacity & Submergence \\
\hline W-W & Waterlogged & Waterlogged \\
W-S & Waterlogged & Submergence \\
\hline
\end{tabular}

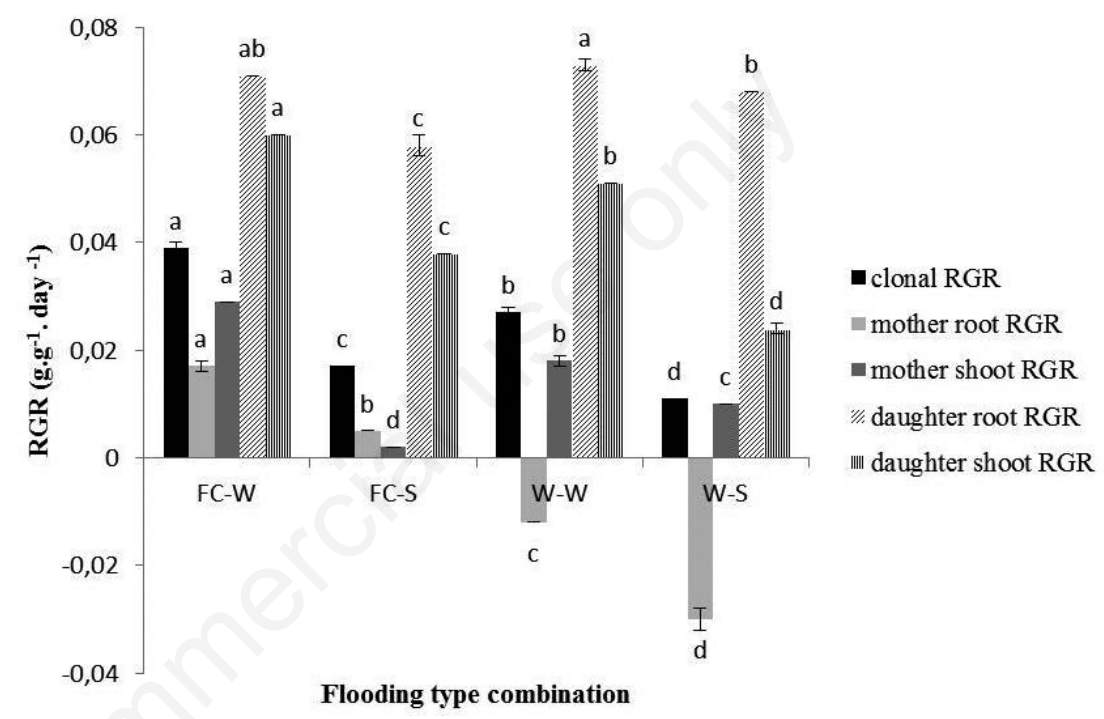

Figure 1. The influence of flooding type combination on clonal RGR, root RGR and shoot RGR $($ mean $\pm S E, n=5)(P<0.05)$.

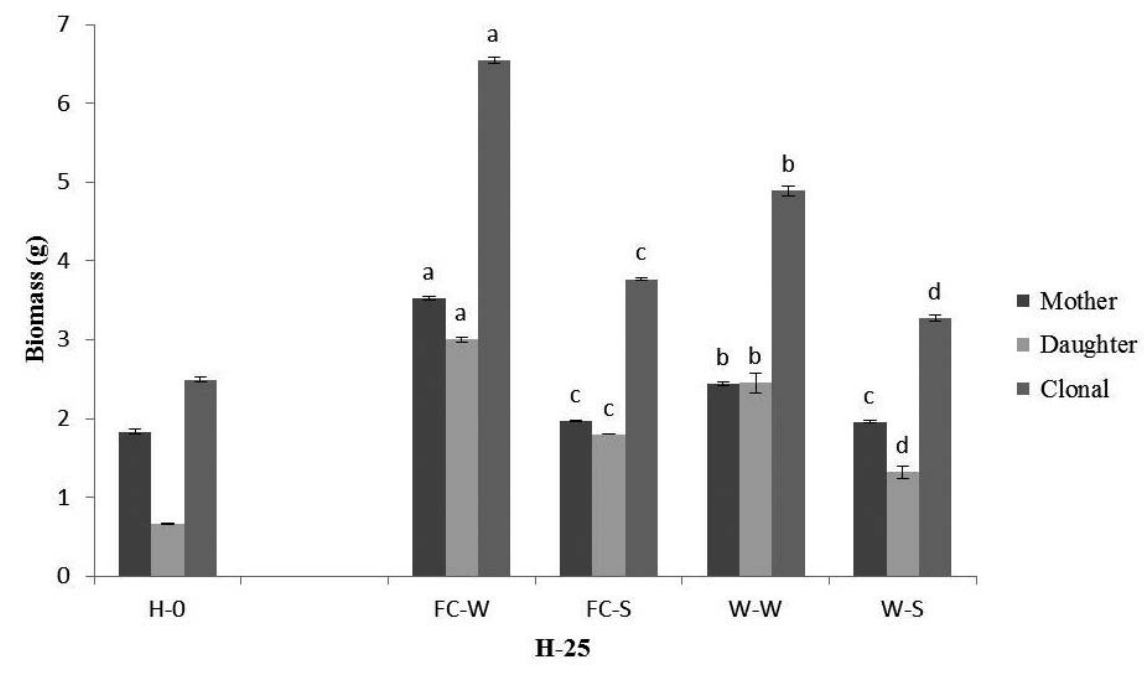

Figure 2. The influence of flooding type combination on biomass. H-0 (mean $\pm S E, n=6)$ is the primary biomass before treatment $(\mathrm{P}<0.05)$. 
allocation was found in the shoots of mother ramet followed by the allocation to the shoots of daughter ramet. The results also showed a decrease in the allocation of biomass in the shoots and roots of the mother ramet, while there was an increase of biomass allocation to roots, shoots and adventitious roots of daughter ramet at FC$\mathrm{W}, \mathrm{FC}-\mathrm{S}$ and $\mathrm{W}-\mathrm{W}$ treatment.

The relative growth rate of root and shoots in mother ramet were lower than in daughter ramet. Moreover, there were decreases in shoot development of all mother ramets. This was related to daughter ramets growth that led to the increase of biomass allocation in the shoot, root, and adventitious root. Again, similar results were found in other clonal plants. As has been reported by Xiao et al., there were increases found in shoot length and biomass accumulation of $S$. alterniflora seedlings under flooding stress. ${ }^{7}$ Several studies show that Fragaria orientalis clonals were survived from drought stress by the support of ramet donors with more resources availability. ${ }^{20}$ Resources translocation was observed in Potamogeton perfoliatus daughter ramets under shade stress, in which the older daughter ramets give their resources to the younger daughter ramets as they need more resources to grow. ${ }^{21}$ Clonal integration facilitates the translocation of resources from rich-resourced ramets to poor-resourced ramets or from source to sink. Moreover, the results show that the direction of resource transport begins in old ramets to young ramets or acropetal. It can be seen in W-W group that had homogenous environmental stress between seedlings. The ramets survival under flooding stress shows that clonal integration strategy supported ramets performance in the heavier stress condition. ${ }^{5}$

For non-clonal plants, waterlogged and submergence conditions inhibit root growth and biomass allocation into the root. ${ }^{18,22}$ These plants tolerate the stress by the formation of adventitious root and lenticel hypertrophy. ${ }^{23,8}$ The adventitious roots are formed by aerenchyma cells to support root function as the lenticel hypertrophy increases $\mathrm{O}_{2}$ diffusion into root cells. ${ }^{23}$

In the waterlogged flooding stress, the root growth rate of mother ramet decreases, but it increases in daughter ramets. The root growth rate of daughter ramets (FC-S and $\mathrm{W}-\mathrm{S}$ ) under submergence flooding stress decreased while the adventitious root increased compared to waterlogged treatments (FC-W and W-W). Moreover, the highest lenticel hypertrophy was found under W-W treatment, followed by W-S, FC-S, and FC-W (Table 2). The growth of adventitious roots in submergence treatments is a strategy to overcome the decrease in root performance. Likewise, the high rate of root growth in the daughter ramets (W-W) due to the development of lenticel hypertrophy. Overall, the clonal integration of $W$. trilobata under flooding type combination leads to the occurrence of morphological adaptation on daughter ramets by forming adventitious root and lenticel hypertrophy. This supports the classical theory that biomass will be allocated mostly to organ with least resources. ${ }^{24}$

The highest shoot growth and biomass of daughter ramets were observed in FC-W group, which is followed by W-W, FC-S and W-S (Table 1; Figure 2). It indicates that submergence flooding stress decreased

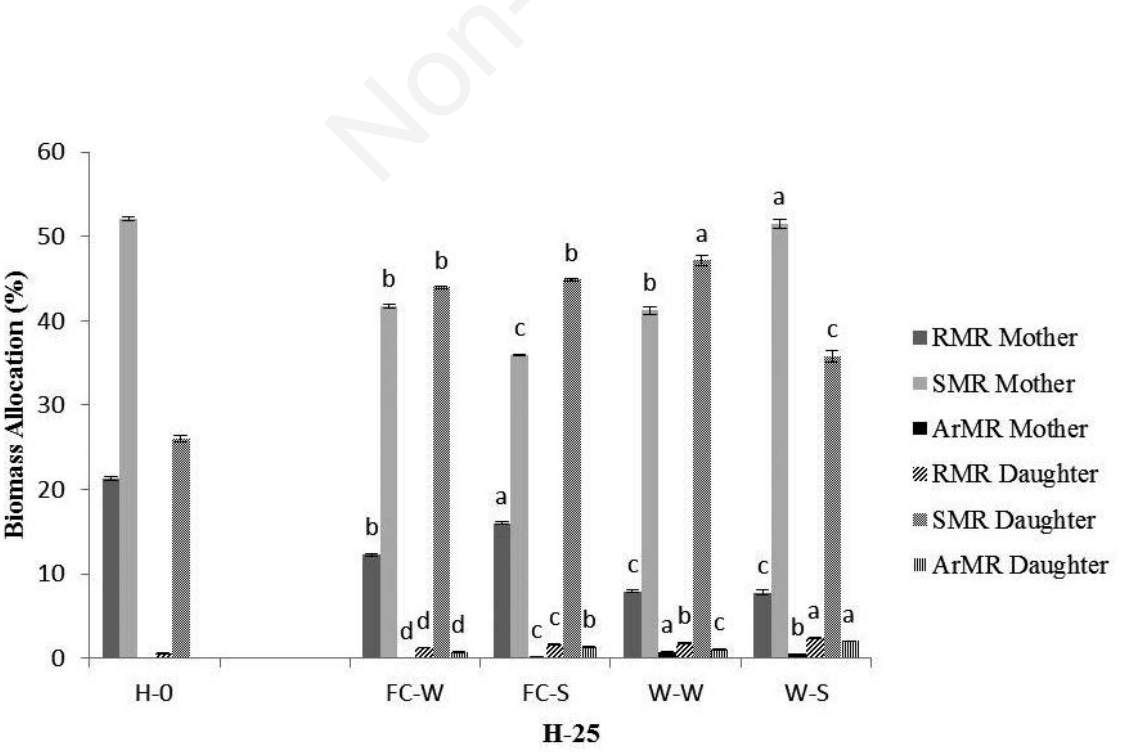

Figure 3. The influence of flooding type combination on biomass allocation. H-0 $($ mean $\pm S E, n=6)$ is the primary biomass before treatment $(P<0.05)$.

the performance of daughter ramets. One of the strategies of plant adaptation towards submergence flooding stress is "the low oxygen escape strategy" (LOES) or increasing respiration and photosynthesis by carbohydrate utilization and increasing cellular metabolism to obtain light and gas $\left(\mathrm{O}_{2}\right.$ and $\left.\mathrm{CO}_{2}\right) \cdot{ }^{8}$ Aerobic conditions under waterlogged flooding stress allow the shoot to perform photosynthesis as the photosynthate will be used in shoot growth (increase stolon length, number, and area of leaves) (Table 1). Therefore, some plants have been reported using LOES strategy, such as Rumex palustris elongates its petiole, ${ }^{25}$ Rorippa amphibia elongates its stem and Alternanthera philoxeroides elongates its internodes, ${ }^{26} \mathrm{~S}$. alterniflora clonal elongates its shoot of daughter ramet to overcome submergence. ${ }^{7}$

The increase of stolon length of FC-S and W-S group were $89.55 \pm 3.47 \%$ and $31.03 \pm 0.8 \%$, respectively, lower than the FC-W and W-W groups (Table 1). However, some of the increase of stolon length can appear above the water surface. Regarding this, the clonal integration improves daughter ramets tolerance under submergence flooding stress through LOES strategy. Moreover, the horizontal growth of W. trilobata is influenced by daughter ramets growth since the relative growth rate in all treatment groups is higher in daughter ramets than in mother ramets.

\section{Conclusions}

Clonal integration supports plant survival under stress of flooding type combination by improving daughter ramets performance. The improvement of daughter ramets performance includes root and shoot growth, biomass allocation, morphological adaptation (adventitious root and lenticel hypertrophy) and LOES strategy. Clonal integration strategy has facilitated $W$. trilobata invasion in areas prone to flooding.

\section{References}

1. Levine JM, Vila M, Antonio CDM, et al. Mechanisms underlying the impacts of exotic plant invasions. Proc Biol Sci 2003;270:775-81.

2. Beck KG, Zimmerman K, Schardt JD, et al. Invasive species defined in a policy context: recommendations from the federal invasive species advisory committee. Invasive Plant Sci Manage 2008;1:414-21. 
3. Liu J, Dong M, Miao SL, et al. Invasive alien plants in China: the role of clonality and geographical origin. Biol Invas 2006;8:1461-70.

4. Oborny B, Mony C, Heben T. From virtual plants to real communities: A review of modeling clonal growth. Ecol Model 2012;234:3-19.

5. Liu F, Liu J, Dong M. Ecological consequences of clonal integration in plants. Front Plant Sci 2016;7:770.

6. Jaafry WH, Li D, Fatima SA, Hassan M. Role of clonal integration among different environmental conditions (a review). Nat Sci 2016;8:475-86.

7. Xiao Y, Tang J, Qing H, et al. Clonal integration enhances flood tolerance of Spartina alterniflora daughter ramets.Aquat Bot 2010;92:9-13.

8. Bailey-Serres J, Lee SC, Brinton E. Waterproofing crops: effective flooding survival strategies. Plant Physiol 2012;160:1698-709.

9. Voesenek LACJ, Bailey-Serres J. Flood adaptive traits and processes: an overview. New Phytol 2015;206:57-73.

10. Si CC, Qi SS, Du DL, et al. Local adaptation and phenotypic plasticity both occurred in Wedelia trilobata invasion across a tropical island. Biol Invas 2014;16:2323-37.

11. Foxcroft LC, Richardson DM, Wilson JRU. Ornamental plants as invasive aliens: problems and solutions in kruger national park, South Africa. Environ
Manage 2008;41:32-51.

12. Qi SS, Dai ZC, Zhai DL, et al. Curvilinear effects of invasive plants on plant diversity: plant community invaded by Sphagneticola trilobata. PLoS One 2014;9.

13. Thaman RR. Wedelia (Sphagneticola trilobata) - daisy invader of the Pacific Islands: the worst weed in the Pacific; 1999. University of the South Pacific, Suva, Fiji Islands. Available from: http://webistem.com/psi.2009/output_d irectory/cd1/Data/articles/000568.pdf

14. Catford JA, Jansson R. Drowned, buried and carried away: effects of plant traits on the distribution of native and alien species in riparian ecosystems. New Phytol 2014;204:19-36.

15. Eckert CG. Clonal plant research: proliferation. Integration, but not much evolution. Am J Bot 1999;86:1649-54.

16. Bailey-Serres J, Voesenek LACJ. Flooding stress: acclimations and genetic diversity. Annu Rev Plant Biol 2008;59:313-39.

17. Xiao Y, Tang J, Zhou C, et al. Trade-offs among growth, clonal, and sexual reproduction in an invasive plant Spartina alterniflora responding to inundation and clonal integration. Hydrobiologia 2011;658:353-63.

18. Zhang Y, Wang Z, Li L, et al. Shortterm complete submergence of rice at the tillering stage increases yield. PLoS One 2015;10.
19. Pezeshki SR, DeLaune RD. Review: soil oxidation-reduction in wetlands and its impact on plant functioning. Biology 2012;1:196-221.

20. Zhang Y, Zhang Q, Sammul M. Physiological integration ameliorates negative effects of drought stress in the clonal HerbFragaria orientalis. PLoS One 2012;7.

21. Wolfer SR, Straile D. To share or not to share: clonal integration in a submerged macrophyte in response to light stress. Hydrobiologia 2012;684:261-9.

22. Ploschuk RA, Grimoldi AA, Ploschuk EL, Striker GG. Growth in recovery evidence the waterlogging tolerance of forage grasses. Crop Pasture Sci 2017;68:574-82.

23. Parent C, Capelli N, Berger A, et al. An overview plant responses to soil waterlogging. Plant Stress 2008;2:20-7.

24. Bloom AJ, Chapin FS, Mooney HA. Resource limitation in plants - an economic analogy. Annu Rev Ecol Syst 1985;16:363-92.

25. Pierik R, Aken JM van, Voesenek LACJ. Is elongation-induced leaf emergence beneficial of submerged Rumex species? Ann Bot 2009;103:353-7.

26. Akman M, Bhikharie AV, McLean EH, et al. Wait or escape? Contrasting submergence tolerance strategies of Rorippa amphibia, Rorippa sylvestris and their hybrid. Ann Bot 2012;109: 1263-76. 